\title{
Genomic sequencing indicates non- random mating of Venturia inaequalis in a mixed cultivar orchard
}

Article

Accepted Version

Passey, T. A. J., Armitage, A. D., Sobczyk, M. K., Shaw, M. W. and Xu, X. (2020) Genomic sequencing indicates non-random mating of Venturia inaequalis in a mixed cultivar orchard. Plant Pathology, 69 (4). pp. 669-676. ISSN 0032-0862 doi: https://doi.org/10.1111/ppa.13150 Available at https://centaur.reading.ac.uk/88904/

It is advisable to refer to the publisher's version if you intend to cite from the work. See Guidance on citing.

To link to this article DOI: http://dx.doi.org/10.1111/ppa.13150

Publisher: Wiley-Blackwell

All outputs in CentAUR are protected by Intellectual Property Rights law, including copyright law. Copyright and IPR is retained by the creators or other copyright holders. Terms and conditions for use of this material are defined in the End User Agreement.

www.reading.ac.uk/centaur 
Central Archive at the University of Reading

Reading's research outputs online 
1 Genomic sequencing indicates non-random mating of Venturia inaequalis in a

2 mixed cultivar orchard

3

4 Authors: Thomas A. J. Passey ${ }^{\mathrm{ab} *}$, Andrew D. Armitage ${ }^{\mathrm{a}}$, Maria K. Sobczyk ${ }^{\mathrm{a}}$, Michael W. Shaw ${ }^{\mathrm{b}}$,

$5 \quad$ Xiangming $\mathrm{Xu}^{\mathrm{a}}$

$6{ }^{a}$ NIAB EMR, New Road, East Malling, Kent, ME19 6BJ, UK; ${ }^{b}$ School of Agriculture, Policy and

7 Development, University of Reading, Reading, RG6 6AR, UK

8 E-mail: tom.passey@emr.ac.uk (Corresponding author)

9

10 Running head: Non-random mating of apple scab fungus 


\section{Abstract}

Apple scab is one of the most economically important diseases of apples worldwide. The disease is caused by the haploid ascomycete Venturia inaequalis. Growing apples in cultivar mixtures may reduce disease severity. To determine how the pathogen population structure is affected by host mixtures we studied $24 \mathrm{~V}$. inaequalis isolates sampled from three different apple cultivars ("Bramley", "Cox" and "Worcester") growing in a mixed orchard approximately 50 years old. The isolates were aligned against a reference genome and single nucleotide polymorphisms (SNPs) were called between the isolates. The populations isolated from Bramley and Worcester were distinct, while Cox isolates were an admixture. This supports previous tests of the ability of isolates to cross-infect hosts, and molecular comparisons using simple sequence repeats (SSRs). Genotype specific allele (GSA) loci were not distributed randomly across contigs in proportion to contig length, but were clustered. Clustered GSA were observed in almost all contigs. This indicates population differentiation across the whole genome, presumably due to lack of crossing-over events between Bramley and Worcester isolates. This lack is probably due to physical separation effects: sexual mating is more likely to take place and succeed between isolates from lesions on the same leaf than from contact between independently infected leaves in leaf litter on the orchard floor. This would especially be the case if sexual reproduction is initiated before leaf-fall. 


\section{Introduction}

The ascomycete Venturia inaequalis is the causal agent of apple scab, one of the most important diseases of apples worldwide (MacHardy, 1996). The primary inoculum of the pathogen is predominantly from sexually produced ascospores released from overwintered leaf litter, although, probably depending on climate, some may be from overwintering asexual conidia (Holb et al., 2004, 2005; Passey et al., 2017). If not adequately managed, rounds of secondary infections from conidia can result in large numbers of unmarketable fruit due to unsightly lesions and regular high incidence can lead to premature leaf fall, reduced cumulative growth and very low yields (MacHardy, 1996). Sufficient control to achieve high quality scab-free fruit requires optimum use of numerous fungicide spray rounds through orchard monitoring and disease forecasting systems.

An alternative, or supplementary, method of disease control is the use of mixing together cultivars of a crop with differing resistance factors (Wolfe, 1985; Mundt, 2002). The potential for cultivar mixtures to reduce scab development in apple orchards was first assessed by simulation (Blaise \& Gessler, 1994)and then tested with a field trial (Bousset et al., 1997). The field trial mixed susceptible and R-gene carrying resistant cultivars and provided evidence that the number of scab lesions per shoot was lower on cv. Golden Delicious and Elstar in mixtures than when these cultivars were in monoculture. The potential of mixtures for scab management was further investigated with a combination of the susceptible cultivar Smoothee and the Rvi6 R-gene carrying cultivar Baujade (Didelot et al., 2007). Scab leaf incidence was reduced on cv. Smoothee in mixture by $7-21 \%$ compared with the mean of monoculture plots, while scab leaf severity was reduced by $15-35 \%$, depending on mixture type and annual epidemic severity. Parisi et al. (2013) investigated scab levels in a mixed orchard of cv. Melrouge, a low susceptibility cultivar, and Pitchounette, a resistant cultivar 
again carrying the Rvi6 gene. In 2008 they found $9 \%$ of scabbed fruits at harvest in a mixed orchard compared with a mean of $15 \%$ in pure stands. In the following year, conditions led to much greater incidence; this was slightly reduced in the mixed orchard, $76 \%$ compared with $82 \%$ in the pure stands.

These studies involved mixing a susceptible cultivar with an R-gene carrying cultivar; however, susceptible cultivars are also known to have differential resistance to apple scab (Sierotzki et al., 1994; Koch et al., 2000). Barbara et al. (2008) showed that isolates of scab sampled from different susceptible cultivars growing within the same orchard could not necessarily infect all other cultivars present. Laboratory crossing between such isolates led to ascospore progenies containing individuals that could infect the whole range of cultivars present in the orchard. Using simple sequence repeat (SSR) markers to look for changes in the $V$. inaequalis populations on the different cultivars indicated that the genetic distances among the populations did not reduce over about a decade, indicating lack of recombination between isolates from different cultivars (Passey et al., 2016). Several hypotheses could

We have obtained further genomic data to confirm this inference of non-random mating. 
mixed orchard to identify single nucleotide polymorphisms (SNPs) present for subsequent investigation of population differentiation. Of these SNPs, we identified those which had the same allele among isolates from a particular host cultivar, but had a different allele in all isolates from another cultivar; we refer to the alleles at these SNP loci as genotype (cultivar) specific alleles (GSA). We tested whether these GSA loci on each contig were randomly distributed in respect to isolate origin (i.e. cultivars) to infer the nature of mating among isolates from different cultivars.

\section{Materials and methods}

\section{Isolates and DNA extraction}

Ash Farm, Worcestershire, UK has a 6-row mixed orchard of Malus x domestica cv. Bramley's Seedling (Bramley), cv. Cox's Orange Pippin (Cox) and cv. Worcester Pearmain (Worcester) on a non-dwarfing rootstock. Each cultivar has two rows with no cultivar being in consecutive rows - Worcester, Cox, Bramley, Cox, Bramley, Worcester. This orchard is ca. 4550 years old. It has never been sprayed and has not recently been pruned. Scab lesions were sampled from this orchard in 2005 and single spore isolates obtained with no two isolates from the same shoot (Xu et al., 2013). In previous work DNA was extracted from freeze-dried mycelia of single spore isolates for comparison of scab populations on the different cultivars using SSR markers (Passey et al., 2016). The eight isolates from each of the three cultivars with the highest DNA concentrations [quantified and quality-checked using a Nanodrop 1000 spectrophotometer (Thermo Scientific)] were selected for Next Generation Sequencing (NGS) on the Illumina MiSeq platform (Supplementary table A). 


\section{Library preparation and sequencing}

Paired-end genomic libraries were prepared using NEXTflex Rapid DNA-Seq library prep kit Version 14.02 (Bioo Scientific) following the manufacturer's protocol modified by using Illumina adapters rather than the NEXTflex Barcodes. Libraries were validated using a Fragment Analyzer (Advanced Analytical Technologies) confirming a high proportion of library DNA fragments between 600 and 900 bp long. Library concentrations were quantified using a Qubit 2.0 (Invitrogen/Thermo Fisher), standardised to $9 \mathrm{nM}$ before pooling and then diluted to $4 \mathrm{nM}$ (libraries of 5 isolates). Denatured, pooled libraries at $20 \mathrm{pM}$ were sequenced using 300 bp reads on an Illumina MiSeq.

\section{Alignment of MiSeq reads to reference genome and SNP calling}

MiSeq reads for all of the isolates were trimmed to remove adaptors and poor quality data from the sequences using fastq-mcf v1.04.636 (Aronesty, 2013). Read depth was calculated per bp using aligned sequence reads using the SAMtools v.1.3.1 depth function, and Median read coverage determined from these values. Alignment of the trimmed reads of the isolates to the reference genome of isolate 05/172 (Passey et al., 2018) was performed with Bowtie2 (Langmead \& Salzberg, 2012). After removing multimapping and discordant reads from the isolates with SAMtools v.1.3.1, SNPs were called with GATK v.3.6 (Van der Auwera et al., 2013) and then filtered to retain only high-quality, biallelic SNPs using the vcffilter function from vcflib and setting the following filtering options: Minimum quality (phred-scaled probability of a SNP occurring at the site) of 40, minimum MQ (phred-scaled probability that the read is mapped to the correct location) of 30 , minimum depth of 10 and minimum $\mathrm{GQ}$ (phred-scaled probability that the sample genotype being called is correct, given that there is a SNP at that site) of 30. VCFTools (Danecek et al. 2011) was used to remove indels and missing data for genetic analyses. 
Previous work comparing isolates from this orchard using AFLP and SSR screening clearly showed a difference between isolates from different cultivars, particularly between Bramley and Worcester (Xu et al., 2013). To confirm this differentiation was true of isolates genomewide, identity-by-state (IBS) was calculated based on the percentage similarity of shared alleles between samples to produce a SNP matrix, visualised using R as a heatmap, based on all SNPs after removal of missing data but without quality filtering. A neighbour joining (NJ) tree based on 1000 bootstrap replicates was produced using the ape package in $R$ and visualised using Figtree ver.1.4.3, to show unrooted phylogeny of the isolates after both removal of missing data and quality filtering.

For isolates originating from the three different cultivars we ran pairwise searches (i.e. isolates from Bramley and Cox; Bramley and Worcester; Cox and Worcester) for those SNPs where isolates from a single host cultivar shared the same allele at a locus, but the allele differed from those in isolates from other populations (i.e. GSAs), using a custom Python script. The number and positions of all SNP loci, GSA loci, GSA loci in genes and nonsynonymous GSA loci in genes were recorded for each contig.

\section{Aggregation of GSA loci}

Those remaining GSA loci after removal of missing data and quality filtering were analysed for aggregation. The number of GSA loci between Bramley and Cox, and between Cox and Bramley, was small. Thus subsequent aggregation analysis of GSA loci was only applied to the GSA loci distinguishing Bramley and Worcester isolates.

Number of GSAs within a contig: We wanted to assess whether the GSA loci in the Bramley and Worcester isolates were randomly distributed among and within the contigs, given the number of total SNP loci in each contig. 
We ran a permutation test to test for aggregation of GSA loci. Specifically, we tested

whether the observed variance in the number of GSA loci between contigs was greater than expected under the assumption of random positioning of GSA loci, conditioned on the total number of SNP loci in the Bramley and Worcester isolates in each contig. We excluded contigs with fewer than 100 SNP loci within the Bramley and Worcester isolates from the permutation test. Such contigs are likely to be either highly conserved regions of DNA and therefore unrepresentative, or poorly sequenced (leading to SNPs being removed during filtering).

Each permutation consisted of the following steps: (i) the observed number of SNP loci of all types in the first contig were randomly sampled from the entire set of SNP loci in the Bramley and Worcester isolates (initial source of SNP loci), without replacement; (ii) the number of GSA loci in this random sample of SNP loci was counted; (iii) the sampled SNP loci were removed from the initial source of SNP loci (i.e. sampling without replacement) to form the new source for subsequent sampling; (iv) the above three steps were repeated on the next contig until random samples for all contigs had been constructed; (v) finally, variance in the number of GSA loci on each contig was calculated. A total 999 permutations were conducted to generate a frequency distribution of variance in the number of GSA loci expected under the assumption of random distribution of GSA loci among contigs. The observed variance in the number of GSA loci among the contigs was then compared with the distribution of 999 simulated variances to estimate a $p$-value.

Distribution of GSA loci within a contig: If GSA loci have inter-dependent functions whether to do with host specificity or not - we would expect selection to maintain them as blocks. The selection required would be weaker in relation to a given degree of crossing if the loci were close together (namely crossing-over events among these loci are less 
frequently, hence more progeny ascospores will inherit the full set of loci). We used a permutation test to assess whether individual GSA loci were randomly distributed within a contig conditioned on the number of SNP loci observed on each contig. Non-GSA SNP loci were coded ' 0 ' while GSA loci were coded ' 1 ' as for a run test (Sprent \& Smeeton, 2007). As before, we excluded contigs with less than 100 SNPs from the permutation analysis. For each permutation, the observed number of GSA loci on each contig was randomly distributed among the positions of all the SNP loci on the contig. Next, the number of consecutive $1 \mathrm{~s}$ (i.e., GSAs) was calculated for two consecutive 1 s up to eleven consecutive 1 s. Only nonoverlapping consecutive $1 \mathrm{~s}$ were counted; thus, for instance, ' 1111 ' had two counts of ' 11 ' and one count each of ' 111 ' and ' $1111^{\prime}$, rather than three counts of ' 11 ', two counts of ' 111 ' and one count of ' 1111 '. This process of redistributing GSAs and counting consecutive GSAs was repeated 1000 times for each contig. The maximum number of two consecutive $1 \mathrm{~s}$ up to eleven consecutive 1s from the 1000 permutations was calculated and compared to the observed value for each contig.

\section{Results}

\section{Genetic structure}

Isolates 05/036, 05/057 (both isolated from Bramley) and 05/118 (isolated from Cox) had insufficient sequencing coverage and had to be removed from the analyses (Supplementary Table A). Isolates from Bramley grouped separately in neighbour-joining cluster diagrams from isolates from Worcester while isolates from Cox appear to be a mixture, thus supporting previous findings with SSRs (Figures 1 and 2). Due to stringent filtering of SNPs to allow analyses with only the best quality data, the NJ tree (Figure 2) shows some very closely 
related isolates as identical, however when looking at unfiltered SNPs there are no isolates

that have an identical set of SNPs.

201

No GSA loci were observed between populations from Cox (7 samples) and Worcester (8 samples), while 160 GSA loci ( $0.03 \%$ of all SNP loci) were found between Cox and Bramley (6 samples) populations, and 7168 (1.15\% of all SNP loci) between Bramley and Worcester

(Table 1). Of the GSA loci between populations from Bramley and Worcester, 3821 (53\%) were in the regions of predicted genes, of which 1019 (27\%) were nonsynonymous. These proportions are similar to those found among all SNPs: $50 \%$ in genes with $28 \%$ of these nonsynonymous. The breakdown of total SNP and GSA loci for individual contigs is given in Supplementary table B.

Aggregation of GSAs

Number of GSAs within a contig between Bramley and Worcester: After removal of contigs with less than 100 SNP loci, $99.96 \%$ of SNP loci remained, across 92 contigs and covering $90.4 \%$ of the total genome length. The GSA loci were extremely aggregated in particular contigs (Permutation test $\mathrm{P}<0.001 ;$ Fig. 3).

Distribution of GSAs within a contig: In all contigs with more than 100 SNP loci, the observed number of consecutive GSA loci was much greater than the maximum of the corresponding values in all the 1000 permutations (Supplementary Table C). For example, for contig 47 (Supplementary information D) in 1000 permutations, two consecutive GSAs occurred a maximum 17 times (122 observed), three consecutive GSAs a maximum three times (77 observed) and just once four consecutive GSA loci (53 observed); but the observed contig had a single run of 52 consecutive GSA loci.

Across all contigs, the most consecutive GSA loci observed in 1000 permutations was six, 
with 121 consecutive GSA loci. Contig 8 was $1.5 \mathrm{Mb}$ long (2.0\% of the genome) and has a

224

225

226

227

228

229

230

231

232

233

234

235

236

237

238

239

240

241

242

243

244

245

total of 13,278 SNPs within the combined Bramley and Worcester populations $(2.1 \%$ of all SNPs across the genome), of which 339 were GSA loci (4.7\% of all GSAs across the genome). However, $70 \%$ of contig 8 GSA loci were between positions 770024 and 781706 , comprising only $0.8 \%$ of the total contig length.

\section{Discussion}

We compared the DNA sequences of isolates of $V$. inaequalis taken from three different cultivars within a single 50 year-old mixed orchard. Isolates from Bramley and Worcester were clearly distinguishable by a large number of SNPs found on many contigs. This supports previous evidence for separation between isolates derived from Bramley and Worcester, based on artificial inoculation studies (Barbara et al., 2008) and molecular comparisons using SSRs (Xu et al., 2013). However, few GSAs separated Cox from either Worcester or Bramley. This also supports previously published evidence. Although the sample sizes in this study were small and therefore some loci with apparent GSA will not actually host GSAs, the permutation tests allow for this, and the lack of GSA between Cox and the other varieties acts as a control for the level of this effect.

The mixed orchard where scab isolates were sampled has not received any sanitation or leaf degradation management. Thus, there have been plenty of fallen leaves from all cultivars on which sexual processes of $V$. inaequalis are believed to take place (MacHardy, 1996). Any explanation for the observed genetic structure needs to be consistent with the fact that the populations studied here have been in spatial proximity for at least 50 rounds of sexual reproduction. There are two broad classes of explanation. First, host specificity 
could act as a barrier to gene flow between the populations by selecting for specific alleles and combinations of alleles. Second, the populations on each host may not in practice interbreed with populations from other hosts, preserving both chance founder effects and GSA not necessarily associated with host specificity. This could be for physical or genetic reasons. These mechanisms for intra-species differentiation as observed in the present study are similar to speciation in the Venturia genus on different host species (Le Cam et al., 2002; Giraud et al., 2010).

We consider first whether host specificity can explain the results. Previously, we showed that fungal population differences in the same mixed orchard decreased over time between Cox and Bramley, but increased in the same period between Bramley and Worcester (Passey et al., 2016). In vitro crossing has shown that 1)there are no physiological barriers to sexual Cox-Worcester or Cox-Bramley mating from infecting Cox, so that little or no indirect gene 
cultivars are commonly regarded as susceptible to scab, partial resistance evidently exists in all three. However, in the same orchard, seven out of 53 viable ascospores from three crosses between isolates from Cox, Bramley and Worcester could already infect both Bramley and Worcester with no obvious difference in lesion development (Barbara et al., 2008). It is hard to reconcile this with a considerable fitness cost across ca. $90 \%$ of the whole genome.

A small proportion of overwintering inoculum could be conidia (Passey et al., 2017). However, this would not maintain GSA if sexual reproduction were able to move alleles from one variety to another. In addition, it is unlikely that asexual overwintering is restricted to a completely separate sub-group of the $V$. inaequalis population. It is more likely that some individuals overwinter as mycelia due to largely chance factors.

A final possibility is that chromosomal rearrangements, such as translocations or inversions, have led to lethality of some recombinants. If several epistatic loci are required for virulence on Worcester, rearrangements holding them together would be favoured. This is hard to test without a fully assembled genome. It would mean that the results here are not general, but depend on specific chromosomal rearrangements in these $V$. inaequalis populations.

Taken together, these arguments suggest that rather than being caused by selection in the presence of gene-flow, the genetic structure is consistent with an absence of (or very infrequent) recombination between isolates on different host cultivars. This is possible if sexual mating is more likely to succeed between isolates infecting the same leaf than between isolates from different leaves after leaf-fall. If sex is initiated before leaf-fall, only isolates with similar genetic backgrounds for virulence have the opportunity to mate. Even if sexual mating is initiated on fallen leaves, the chance of successful mating is still likely to be 
much higher between isolates on the same leaf than isolates on different leaves, since sufficient close contact time to initiate the mating process will be much more likely. Further research is necessary to investigate when mating is initiated relative to leaf fall and the minimum contact time between isolates from different leaves required to initiate the mating process. If the hypothesis of minimal sexual mating among isolates that infected different leaves is correct, there are significant implications for understanding pathogen evolution and practical disease management, such as the timing of end-of-season control measures to reduce sexual reproduction and therefore primary inoculum the following season.

The number of GSA loci separating the isolates from Cox and isolates of the other two cultivars was very low. This is consistent with the isolates of Cox being a mixture, with some isolates grouping more closely with isolates from Bramley and some more closely with isolates from Worcester (Fig 2). This hypothesis is supported both by artificial inoculation studies (Barbara et al., 2008) and by population comparisons based on SSR markers (Xu et al., 2013; Passey et al., 2016). However, it means that, unless these two sub-populations are separated in some way, isolates virulent on both Bramley and Worcester via the Cox isolates as a mating partner and with the alternate allele at the genome specific allele should arise by recombination, giving rise to "super-race" isolates virulent on all the cultivars in the mixture. It is an important consideration in establishing a mixed cultivar orchard that the cultivars 312 have differing resistance factors. Although we have no evidence for a breakdown in the difference between Bramley and Worcester in this orchard, this may be due to specific factors due to the particular varieties mixed. In particular, the maintenance of separate CoxBramley and Cox-Worcester groupings in the Cox population could be explained by chromosomal rearrangements, with the loci conferring virulence lying within an inverted or 
318 for the rearranged regions. The proportion of the genome involved in, or affected by, 319 rearrangements would be extensive but not unprecedented (Raeside et al., 2014; Shi-Kunne 320 et al., 2018; Olarte et al., 2019). As pointed out above, chromosomal rearrangements would, 321 of course, also be another explanation for the aggregation of GSAs. In general, therefore, 322 despite the present results, it would be prudent not to have a potential intermediate 323 cultivar.

324 Conidia are likely to have a role as part of the primary inoculum in some regions (Holb et al., 2004, 2005; Passey et al., 2017). If climate of the study orchard does not favour ascospore production and so only asexual clonal races of the pathogen are present, this could also explain the differentiation between Worcester and Bramley, even with an intermediate cultivar, Cox, present. However, this is highly unlikely. Although no pseudothecia have ever been recovered in areas of Israel that lack the necessary lower winter temperatures (Boehm et al., 2003), there is no indication that this happens in orchards in temperate regions and all the evidence is that ascospores are, at least, an important source of inoculum in these areas.

If mating among scab isolates within an orchard is not random because the opposite mating types have to be able to infect the same host, this would reduce the rate at which virulence factors against different resistance genes can recombine. This could explain how populations on different cultivars within the same orchard remain different after ca. 50 years of sexual reproduction, though less obviously how the Cox population remains sub-divided. decrease levels of apple scab compared to monoculture (Didelot et al., 2007; Parisi et al., 2013), is a more attractive option if the risk of "super-races", combining virulence on all components of a mixture, emerging is much less than predicted on the assumption of 
random mating across cultivars. The risk is further reduced if orchards are replaced after short periods: current commercial apple orchards are replaced after only 15-20 years. cultivars within a mixed orchard do not mate at random. We suggest that the most likely explanation is a low frequency of mating between isolates initially infecting different leaves, though other explanations are possible. This separation of sub-populations suggests that the risk of super-races in mixed orchards may be low enough for mixtures that reduce apple scab to remain viable for the lifetime of commercial orchards (15-20 years). A similar conclusion would follow for other pathosystems requiring hyphal mating on living tissue.

\title{
Acknowledgements
}

The authors would like to thank Tony Roberts for sample collection and single spore isolations and Dr Richard Harrison for his ideas and advice. This research was funded by the British Department for Environment, Food and Rural Affairs (Defra) and the National Association of Cider Makers (NACM).

\section{Data availability}

The data that support the findings of this study are available from the corresponding author upon reasonable request.

Aronesty E, 2013. Comparison of Sequencing Utility Programs. The Open Bioinformatics

\section{References}

\author{
Journal 7, 1-8. \\ Van der Auwera GA, Carneiro MO, Hartl C et al., 2013. From FastQ data to high-confidence
}


variant calls: The genome analysis toolkit best practices pipeline. In: Current Protocols in Bioinformatics. Hoboken, NJ, USA: John Wiley \& Sons, Inc., 11.10.1-11.10.33.

Barbara DJ, Roberts AL, Xu X-M, 2008. Virulence characteristics of apple scab (Venturia inaequalis) isolates from monoculture and mixed orchards. Plant Pathology 57, 552561.

Blaise P, Gessler C, 1994. Cultivar mixtures in apple orchards as a mean to control apple scab? Norwegian Journal of Agricultural Sciences 17, 105-112.

Boehm E, Freeman S, Shabi E, Michailides T, 2003. Microsatellite primers indicate the presence of asexual populations of Venturia inaequalis in coastal Israeli apple orchards. Phytoparasitica 31, 236-251.

Bousset L, Blaise P, Kellerhals M, Gessler C, 1997. Mixtures of apple cultivars in orchards: effect on the scab epidemics. IOBC/WPRS Bulletin 20, 42-48.

Le Cam B, Parisi L, Arene L, 2002. Evidence of two formae speciales in Venturia inaequalis, responsible for apple and pyracantha scab. Phytopathology 92, 314-20.

Didelot F, Brun L, Parisi L, 2007. Effects of cultivar mixtures on scab control in apple orchards. Plant Pathology 56, 1014-1022.

Giraud T, Gladieux P, Gavrilets S, 2010. Linking the emergence of fungal plant diseases with ecological speciation. Trends in ecology \& evolution 25, 387-95.

Holb I, Heijne B, Jeger M, 2004. Overwintering of conidia of Venturia inaequalis and the contribution to early epidemics of apple scab. Plant Disease 88, 751-757.

Holb IJ, Heijne B, Jeger MJ, 2005. The widespread occurrence of overwintered conidial inoculum of Venturia inaequalis on shoots and buds in organic and integrated apple orchards across the Netherlands. European Journal of Plant Pathology 111, 157-168.

Koch T, Kellerhals M, Gessler C, 2000. Virulence pattern of Venturia inaequalis field isolates and corresponding differential resistance in Malus $\mathrm{x}$ domestica. Journal of Phytopathology 148, 357-364.

Langmead B, Salzberg SL, 2012. Fast gapped-read alignment with Bowtie 2. Nature Methods 9, 357-359.

MacHardy WE, 1996. Apple Scab: Biology, Epidemiology, and Management. St Paul, MN: American Phytopathological Society.

Mundt CC, 2002. Use of multiline cultivars and cultivar mixtures for disease management. Annual Review of Phytopathology 40, 381-410.

Olarte RA, Menke J, Zhang Y et al., 2019. Chromosome rearrangements shape the diversification of secondary metabolism in the cyclosporin producing fungus Tolypocladium inflatum. BMC Genomics 20, 120.

Parisi L, Gros C, Combe F, Parveaud C-E, Gomez C, Brun L, 2013. Impact of a cultivar mixture on scab, powdery mildew and rosy aphid in an organic apple orchard. Crop Protection 43, 207-212.

Passey TAJ, Armitage AD, Xu X, 2018. Annotated Draft Genome Sequence of the Apple Scab Pathogen Venturia inaequalis. Microbiology Resource Announcements 7.

Passey TAJ, Robinson JD, Shaw MW, Xu X-M, 2017. The relative importance of conidia and ascospores as primary inoculum of Venturia inaequalis in a southeast England orchard. Plant Pathology.

Passey TAJ, Shaw MW, Xu X-M, 2016. Differentiation in populations of the apple scab fungus Venturia inaequalis on cultivars in a mixed orchard remain over time. Plant Pathology 
65, 1133-1141.

Raeside C, Gaffé J, Deatherage DE et al., 2014. Large chromosomal rearrangements during a long-term evolution experiment with Escherichia coli. mBio 5, e01377-14.

Shi-Kunne X, Faino L, van den Berg GCM, Thomma BPHJ, Seidl MF, 2018. Evolution within the fungal genus Verticillium is characterized by chromosomal rearrangement and gene loss. Environmental Microbiology 20, 1362-1373. variation in virulence toward susceptible apple cultivars in natural populations of Venturia inaequalis. Phytopathology 84, 1005-1009.

Sprent P, Smeeton NC, 2007. Applied nonparametric statistical methods. Chapman \& Hall/CRC.

Wolfe MS, 1985. The current status and prospects of multiline cultivars and variety mixtures for disease resistance. Annual Review of Phytopathology 23, 251-273.

Xu X, Harvey N, Roberts A, Barbara D, 2013. Population variation of apple scab (Venturia inaequalis) within mixed orchards in the UK. European Journal of Plant Pathology 135, 97-104. 
Supplementary table A. Venturia inaequalis isolates from Ash Farm, UK, a mixed cultivar orchard of Bramley, Cox and Worcester. Genomes of all isolates were sequenced on the

431 Illumina platform.

Supplementary table B. The whole genome sequence (WGS) of $14 \mathrm{~V}$. inaequalis isolates (6 from Bramley, 8 from Worcester) were aligned to the 05/172 reference genome (one of the 8 Worcester isolates). The total number of SNPs between the 14 isolates were called and then the number of genotype specific polymorphic alleles (GSAs) (i.e. isolates from Bramley shared the same allele at a locus but this differed to that shared among the Worcester isolates) in the whole genome, those just in genes and those nonsynonymous.

C. Number in brackets is the maximum number of consecutive genotype specific allelic (GSA) loci in a contig from 1000 permutations of the allocation of GSA to positions occupied by a single nucleotide polymorphism. A lack of number on top row for each contig indicates there was no occurrence in the permutation for that number of consecutive GSA loci. The main entry (second row for each contig) is the observed number of consecutive GSA on each contig. Only contigs with any GSA loci presented.

Supplementary information D. An example input data of genotype specific allele (GSA) (1) and non-GSA SNPs (0) of contig 47 for GSA redistribution analysis of GSAs within a contig. sequenced and aligned to the assembled genome of Venturia inaequalis isolate 05/172. 
Figure 1. Heatmap to represent clustering of $21 \mathrm{~V}$. inaequalis isolates from three different apple cultivars, Bramley (B), Cox (C) and Worcester (W), present in the same orchard. Data

451 from identity-by-state (IBS) calculated on the percentage similarity of shared alleles between samples to produce a SNP matrix (the darker the shading the more alike the

453 isolates). Due to rounding percentage values, several isolates showed " $100 \%$ " IBS; examining unfiltered SNPs showed that there are no isolates that have an identical set of SNPs.

Figure 2. A Neighbour joining (NJ) tree, in polar format, showing clustering of Venturia inaequalis isolates from three different apple cultivars, Bramley, Cox and Worcester, present in the same orchard.

Figure 3. Plots of standard deviation of $(A)$ the number of Bramley-Worcester genotype specific allele (GSA) loci and (B) the number of Bramley-Worcester GSA as the percentage of total number of Cox-Bramley-Worcester GSA on each contig under the assumption of random distribution of all the GSA loci across all contigs. The 1000 values consisted of 999 from permutations and the observed values.

Supplementary table A. Venturia inaequalis isolates from Ash Farm, UK, a mixed cultivar orchard of Bramley, Cox and Worcester. Genomes of all isolates were sequenced on the Illumina MiSeq platform

\begin{tabular}{|c|c|c|c|c|}
\hline Isolate ID & Host cultivar & MiSeq run & $\begin{array}{l}\text { Amount of data from } \\
\text { MiSeq run (bp) }\end{array}$ & Coverage $^{c}$ \\
\hline 05/007 & Bramley & 2 & 13136208 & 31 \\
\hline 05/024 & Bramley & 4 & 12453319 & 33 \\
\hline 05/025 & Bramley & 3 & 14340023 & 33 \\
\hline 05/030 & Bramley & 4 & 11430665 & 28 \\
\hline 05/036 & Bramley & 5 & 2029822 & $3^{d}$ \\
\hline 05/044 & Bramley & 2 & 19637369 & 45 \\
\hline 05/049 & Worcester ${ }^{b}$ & 1 & 13700931 & 39 \\
\hline 05/057 & Bramley & 1 & 13336096 & $10^{d}$ \\
\hline 05/083 & Cox & 2 & 12003095 & 29 \\
\hline
\end{tabular}




\begin{tabular}{lllrr}
$05 / 096$ & Cox & 3 & 13063352 & 4641 \\
$05 / 097$ & Cox & 5 & 12123271 & 27 \\
$05 / 098$ & Cox & 1 & 17982080 & 52 \\
$05 / 101$ & Cox & 4 & 13983601 & 37 \\
$05 / 106$ & Cox & 4 & 9259589 & 24 \\
$05 / 118$ & Cox & 3 & 11758642 & $9^{\text {d }}$ \\
$05 / 119$ & Cox & 1 & 14438772 & 38 \\
$05 / 172^{\text {a }}$ & Worcester & 2 & 12672586 & 32 \\
$05 / 173$ & Worcester & 5 & 19115153 & 48 \\
$05 / 182$ & Worcester & 2 & 15752464 & 40 \\
$05 / 190$ & Worcester & 5 & 13003150 & 33 \\
$05 / 196$ & Worcester & 3 & 11826771 & 33 \\
$05 / 197$ & Worcester & 4 & 13898993 & 36 \\
$05 / 199$ & Bramley & 1 & 21335557 & 54 \\
$05 / 202$ & Worcester & 3 & 14365407 & 37 \\
\hline
\end{tabular}

aThe genome of isolate $05 / 172$ was also sequenced by the PacBio platform and used to assemble the reference genome used in this publication.

bIsolates were mislabelled during library prep; this was picked up and checked during data analysis and as such the isolate codes for this publication have been switched; i.e. the isolate in 05/199 in this publication is actually the isolate 05/049 from Bramley and vice versa.

${ }^{\mathrm{c} C}$ Coverage showing median read coverage per bp.

${ }^{d}$ Because of low coverage, these isolates were in population analysis.

Supplementary table B. The whole genome sequence (WGS) of $14 \mathrm{~V}$. inaequalis isolates (6 from Bramley, 8 from Worcester), sequenced on the Illumina Miseq platform, were aligned to the $05 / 172$ reference genome (one of the 8 Worcester isolates). The total number of SNPs between the 14 isolates were called and then the number of genotype specific polymorphic alleles (GSAs) (i.e. isolates from Bramley shared the same allele at a locus but this differed to that shared among the Worcester isolates) in the whole genome, those just in genes and those nonsynonymous

\begin{tabular}{|c|c|c|c|c|c|}
\hline Contig & $\begin{array}{l}\text { Length } \\
\text { (bp) }\end{array}$ & $\begin{array}{l}\text { Total SNPs } \\
\text { in B/W } \\
\text { populations }\end{array}$ & $\begin{array}{l}\text { Total GSA } \\
\text { loci in } \\
\text { genome }\end{array}$ & $\begin{array}{l}\text { GSA loci in } \\
\text { genes }\end{array}$ & $\begin{array}{l}\text { Genotype } \\
\text { specific } \\
\text { nonsynonymous } \\
\text { polymorphic loci } \\
\text { in genes }\end{array}$ \\
\hline 1 & 3847617 & 39750 & 88 & 24 & 6 \\
\hline 2 & 2883036 & 35428 & 367 & 162 & 53 \\
\hline 3 & 2469270 & 25959 & 294 & 156 & 39 \\
\hline 4 & 1643167 & 18383 & 88 & 31 & 10 \\
\hline 5 & 1572910 & 16462 & 483 & 204 & 55 \\
\hline 6 & 1553562 & 13901 & 48 & 21 & 6 \\
\hline 7 & 1545189 & 15053 & 290 & 158 & 27 \\
\hline 8 & 1540187 & 13278 & 339 & 307 & 79 \\
\hline 9 & 1520579 & 11419 & 249 & 120 & 36 \\
\hline 10 & 1471990 & 11801 & 18 & 4 & 0 \\
\hline 11 & 1469107 & 18420 & 209 & 105 & 29 \\
\hline 12 & 1466925 & 16430 & 79 & 32 & 12 \\
\hline
\end{tabular}




\begin{tabular}{|c|c|c|c|c|c|}
\hline 13 & 1444683 & 16911 & 254 & 90 & 29 \\
\hline 14 & 1434827 & 7843 & 47 & 11 & 7 \\
\hline 15 & 1433712 & 13375 & 42 & 24 & 6 \\
\hline 16 & 1432488 & 15795 & 149 & 73 & 19 \\
\hline 17 & 1345551 & 15547 & 176 & 116 & 27 \\
\hline 18 & 1224983 & 11025 & 22 & 11 & 5 \\
\hline 19 & 1201024 & 13765 & 133 & 52 & 13 \\
\hline 20 & 1189902 & 12346 & 529 & 259 & 55 \\
\hline 21 & 989026 & 8262 & 12 & 5 & 3 \\
\hline 22 & 960501 & 13438 & 94 & 48 & 18 \\
\hline 23 & 953805 & 6543 & 61 & 40 & 3 \\
\hline 24 & 887866 & 7589 & 2 & 1 & 1 \\
\hline 25 & 878632 & 7455 & 87 & 38 & 5 \\
\hline 26 & 877845 & 11043 & 11 & 0 & 0 \\
\hline 27 & 830644 & 7224 & 45 & 30 & 4 \\
\hline 28 & 802546 & 8038 & 59 & 48 & 7 \\
\hline 29 & 775226 & 5108 & 49 & 32 & 3 \\
\hline 30 & 757030 & 5133 & 1 & 0 & 0 \\
\hline 31 & 757014 & 4206 & 42 & 13 & 6 \\
\hline 32 & 742314 & 3749 & 62 & 24 & 4 \\
\hline 33 & 713553 & 9208 & 46 & 5 & 4 \\
\hline 34 & 702798 & 6598 & 10 & 4 & 3 \\
\hline 35 & 667479 & 8316 & 14 & 11 & 3 \\
\hline 36 & 664565 & 4321 & 0 & 0 & 0 \\
\hline 37 & 642819 & 6378 & 170 & 94 & 17 \\
\hline 38 & 633838 & 4775 & 3 & 0 & 0 \\
\hline 39 & 631560 & 8285 & 399 & 158 & 36 \\
\hline 40 & 616300 & 5535 & 8 & 0 & 0 \\
\hline 41 & 615051 & 4108 & 0 & 0 & 0 \\
\hline 42 & 612523 & 2330 & 0 & 0 & 0 \\
\hline 43 & 606529 & 8417 & 25 & 13 & 8 \\
\hline 44 & 599691 & 7232 & 81 & 45 & 25 \\
\hline 45 & 572125 & 7163 & 237 & 171 & 62 \\
\hline 46 & 570550 & 7497 & 257 & 151 & 28 \\
\hline 47 & 548817 & 8366 & 270 & 193 & 33 \\
\hline 48 & 544245 & 5585 & 231 & 141 & 34 \\
\hline 49 & 531805 & 7819 & 42 & 36 & 9 \\
\hline 50 & 510422 & 1584 & 0 & 0 & 0 \\
\hline 51 & 486582 & 2049 & 2 & 1 & 1 \\
\hline 52 & 483498 & 4553 & 1 & 0 & 0 \\
\hline 53 & 467987 & 1618 & 0 & 0 & 0 \\
\hline 54 & 448816 & 6344 & 175 & 98 & 48 \\
\hline 55 & 403330 & 2362 & 1 & 0 & 0 \\
\hline 56 & 400139 & 3177 & 18 & 11 & 5 \\
\hline 57 & 386935 & 1347 & 1 & 0 & 0 \\
\hline 58 & 359892 & 4218 & 107 & 61 & 20 \\
\hline
\end{tabular}




\begin{tabular}{|c|c|c|c|c|c|}
\hline 59 & 347592 & 2998 & 1 & 0 & 0 \\
\hline 60 & 334733 & 2927 & 0 & 0 & 0 \\
\hline 61 & 334267 & 2826 & 1 & 0 & 0 \\
\hline 62 & 316014 & 1835 & 0 & 0 & 0 \\
\hline 63 & 307156 & 4892 & 4 & 0 & 0 \\
\hline 64 & 259082 & 2355 & 1 & 0 & 0 \\
\hline 65 & 255655 & 2879 & 235 & 152 & 37 \\
\hline 66 & 249385 & 2827 & 2 & 1 & 1 \\
\hline 67 & 246485 & 1439 & 77 & 37 & 13 \\
\hline 68 & 243293 & 2172 & 112 & 93 & 17 \\
\hline 70 & 239636 & 796 & 0 & 0 & 0 \\
\hline 71 & 239618 & 1123 & 2 & 1 & 1 \\
\hline 72 & 238937 & 2896 & 53 & 16 & 1 \\
\hline 73 & 236519 & 2721 & 0 & 0 & 0 \\
\hline 74 & 227977 & 1006 & 2 & 2 & 2 \\
\hline 75 & 223988 & 1210 & 0 & 0 & 0 \\
\hline 76 & 222240 & 1059 & 29 & 15 & 11 \\
\hline 77 & 205344 & 1583 & 2 & 0 & 0 \\
\hline 79 & 194393 & 1952 & 0 & 0 & 0 \\
\hline 80 & 193792 & 10 & 0 & 0 & 0 \\
\hline 81 & 190172 & 79 & 0 & 0 & 0 \\
\hline 82 & 189157 & 1573 & 4 & 4 & 0 \\
\hline 83 & 188550 & 1504 & 21 & 6 & 4 \\
\hline 85 & 173860 & 1172 & 0 & 0 & 0 \\
\hline 86 & 165300 & 764 & 0 & 0 & 0 \\
\hline 88 & 156979 & 1207 & 1 & 0 & 0 \\
\hline 89 & 148886 & 320 & 0 & 0 & 0 \\
\hline 90 & 145307 & 1200 & 1 & 0 & 0 \\
\hline 91 & 144156 & 783 & 6 & 6 & 5 \\
\hline 92 & 144025 & 1500 & 69 & 44 & 12 \\
\hline 93 & 142133 & 584 & 0 & 0 & 0 \\
\hline 94 & 140254 & 568 & 0 & 0 & 0 \\
\hline 96 & 133811 & 28 & 0 & 0 & 0 \\
\hline 97 & 123707 & 1353 & 1 & 1 & 1 \\
\hline 99 & 110078 & 497 & 0 & 0 & 0 \\
\hline 101 & 98753 & 4 & 0 & 0 & 0 \\
\hline 102 & 89478 & 278 & 1 & 1 & 1 \\
\hline 120 & 60568 & 634 & 16 & 10 & 10 \\
\hline 144 & 44087 & 12 & 0 & 0 & 0 \\
\hline 145 & 43653 & 1 & 0 & 0 & 0 \\
\hline 166 & 34764 & 21 & 0 & 0 & 0 \\
\hline 183 & 29119 & 86 & 0 & 0 & 0 \\
\hline 190 & 28319 & 12 & 0 & 0 & 0 \\
\hline \multicolumn{6}{|l|}{ Remaining } \\
\hline contigs $^{a}$ & 6144191 & 0 & 0 & 0 & 0 \\
\hline Total & 72310420 & 625550 & 7168 & 3821 & 1019 \\
\hline
\end{tabular}


${ }^{\mathrm{a} C}$ Contigs containing no SNPs, equating to $8.5 \%$ of the genome

Supplementary table $\mathbf{C}$. The top row for each contig is the maximum number of consecutive genotype specific allelic (GSA) loci in a contig from 1000 permutations of the allocation of GSA to positions occupied by a single nucleotide polymorphism; the main entry in bold (second row for each contig) is the observed number of consecutive GSA on each contig. Only contigs with any GSA loci presented

\begin{tabular}{|c|c|c|c|c|c|c|c|c|c|c|c|}
\hline \multirow{2}{*}{$\begin{array}{l}\text { Contig } \\
\text { number }\end{array}$} & \multirow{2}{*}{$\begin{array}{l}\text { No. of } \\
\text { GSAs }\end{array}$} & \multicolumn{10}{|c|}{ Number of consecutive Genotype Specific Alleles } \\
\hline & & 2 & 3 & 4 & 5 & 6 & 7 & 8 & 9 & 10 & 11 \\
\hline \multirow[t]{2}{*}{1} & 88 & 3 & 1 & 0 & 0 & 0 & 0 & 0 & 0 & 0 & 0 \\
\hline & & 29 & 15 & 9 & 7 & 5 & 4 & 2 & 2 & 2 & 2 \\
\hline \multirow[t]{2}{*}{2} & 367 & 11 & 1 & 1 & 0 & 0 & 0 & 0 & 0 & 0 & 0 \\
\hline & & 108 & 54 & 29 & 15 & 9 & 8 & 5 & 5 & 3 & 2 \\
\hline \multirow[t]{2}{*}{3} & 294 & 12 & 1 & 0 & 0 & 0 & 0 & 0 & 0 & 0 & 0 \\
\hline & & 111 & 60 & 40 & 29 & 18 & 16 & 12 & 10 & 8 & 7 \\
\hline \multirow[t]{2}{*}{4} & 88 & 4 & 1 & 0 & 0 & 0 & 0 & 0 & 0 & 0 & 0 \\
\hline & & 33 & 15 & 12 & 5 & 3 & 3 & 3 & 1 & 1 & 1 \\
\hline \multirow[t]{2}{*}{5} & 483 & 26 & 4 & 1 & 0 & 0 & 0 & 0 & 0 & 0 & 0 \\
\hline & & 164 & 87 & 56 & 38 & 27 & 21 & 18 & 15 & 14 & 12 \\
\hline \multirow[t]{2}{*}{6} & 48 & 3 & 1 & 0 & 0 & 0 & 0 & 0 & 0 & 0 & 0 \\
\hline & & 12 & 6 & 4 & 4 & 1 & 1 & 1 & 1 & 1 & 1 \\
\hline \multirow[t]{2}{*}{7} & 290 & 15 & 2 & 1 & 0 & 0 & 0 & 0 & 0 & 0 & 0 \\
\hline & & 98 & 52 & 32 & 26 & 20 & 13 & 10 & 8 & 7 & 6 \\
\hline \multirow[t]{2}{*}{8} & 339 & 19 & 2 & 1 & 1 & 0 & 0 & 0 & 0 & 0 & 0 \\
\hline & & 137 & 80 & 57 & 44 & 34 & 27 & 24 & 19 & 16 & 13 \\
\hline \multirow[t]{2}{*}{9} & 249 & 13 & 2 & 1 & 0 & 0 & 0 & 0 & 0 & 0 & 0 \\
\hline & & 87 & 44 & 28 & 17 & 14 & 10 & 9 & 6 & 4 & 4 \\
\hline \multirow[t]{2}{*}{10} & 18 & 1 & 0 & 0 & 0 & 0 & 0 & 0 & 0 & 0 & 0 \\
\hline & & 5 & 2 & 1 & 0 & 0 & 0 & 0 & 0 & 0 & 0 \\
\hline \multirow[t]{2}{*}{11} & 209 & 8 & 2 & 0 & 0 & 0 & 0 & 0 & 0 & 0 & 0 \\
\hline & & 72 & 37 & 22 & 12 & 9 & 5 & 4 & 3 & 3 & 3 \\
\hline \multirow[t]{2}{*}{12} & 79 & 4 & 0 & 0 & 0 & 0 & 0 & 0 & 0 & 0 & 0 \\
\hline & & 25 & 14 & 6 & 4 & 3 & 3 & 1 & 1 & 1 & 1 \\
\hline \multirow[t]{2}{*}{13} & 254 & 11 & 2 & 0 & 0 & 0 & 0 & 0 & 0 & 0 & 0 \\
\hline & & 90 & 49 & 31 & 20 & 16 & 13 & 11 & 9 & 7 & 6 \\
\hline \multirow[t]{2}{*}{14} & 47 & 3 & 0 & 0 & 0 & 0 & 0 & 0 & 0 & 0 & 0 \\
\hline & & 9 & 6 & 2 & 1 & 0 & 0 & 0 & 0 & 0 & 0 \\
\hline \multirow[t]{2}{*}{15} & 42 & 2 & 0 & 0 & 0 & 0 & 0 & 0 & 0 & 0 & 0 \\
\hline & & 17 & 9 & 5 & 3 & 2 & 2 & 1 & 1 & 1 & 1 \\
\hline \multirow[t]{2}{*}{16} & 149 & 5 & 2 & 0 & 0 & 0 & 0 & 0 & 0 & 0 & 0 \\
\hline & & 60 & 38 & 27 & 20 & 18 & 14 & 12 & 11 & 8 & 7 \\
\hline \multirow[t]{2}{*}{17} & 176 & 7 & 2 & 0 & 0 & 0 & 0 & 0 & 0 & 0 & 0 \\
\hline & & 60 & 33 & 23 & 13 & 12 & 8 & 8 & 7 & 5 & 4 \\
\hline \multirow[t]{2}{*}{18} & 22 & 2 & 0 & 0 & 0 & 0 & 0 & 0 & 0 & 0 & 0 \\
\hline & & 6 & 3 & 1 & 1 & 1 & 1 & 0 & 0 & 0 & 0 \\
\hline
\end{tabular}


$\begin{array}{llllllllllll}19 & 133 & 5 & 1 & 0 & 0 & 0 & 0 & 0 & 0 & 0 & 0\end{array}$ $\begin{array}{llllllllll}44 & 19 & 14 & 8 & 6 & 4 & 4 & 3 & 2 & 1\end{array}$ $\begin{array}{llllllllllll}20 & 529 & 37 & 6 & 1 & 1 & 0 & 0 & 0 & 0 & 0 & 0\end{array}$ $\begin{array}{llllllllll}189 & 90 & 55 & 35 & 26 & 18 & 13 & 10 & 9 & 7\end{array}$ $\begin{array}{llllllllllll}21 & 12 & 1 & 0 & 0 & 0 & 0 & 0 & 0 & 0 & 0 & 0\end{array}$ $2 \quad 1 \quad 00 \begin{array}{llllllll}2 & 1 & 0 & 0 & 0 & 0 & 0 & 0\end{array}$ $\begin{array}{llllllllllll}22 & 94 & 5 & 1 & 0 & 0 & 0 & 0 & 0 & 0 & 0 & 0\end{array}$ $\begin{array}{llllllllll}25 & 11 & 8 & 4 & 2 & 2 & 2 & 1 & 1 & 1\end{array}$ $\begin{array}{llllllllllll}23 & 61 & 3 & 1 & 0 & 0 & 0 & 0 & 0 & 0 & 0 & 0\end{array}$ $\begin{array}{llllllllll}20 & 11 & 6 & 3 & 3 & 2 & 2 & 2 & 1 & 1\end{array}$ $\begin{array}{llllllllllll}24 & 2 & 0 & 0 & 0 & 0 & 0 & 0 & 0 & 0 & 0 & 0\end{array}$ $\begin{array}{llllllllllll}25 & 87 & 5 & 1 & 1 & 1 & 0 & 0 & 0 & 0 & 0 & 0\end{array}$ $\begin{array}{llllllllll}32 & 18 & 12 & 9 & 6 & 5 & 4 & 4 & 3 & 2\end{array}$ $\begin{array}{llllllllllll}26 & 11 & 1 & 0 & 0 & 0 & 0 & 0 & 0 & 0 & 0 & 0\end{array}$

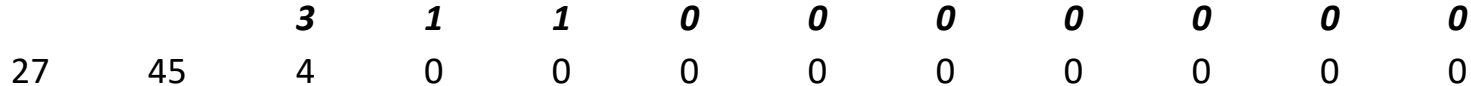
$\begin{array}{rrrrrrrrrr}23 & 12 & 8 & 6 & 4 & 2 & 2 & 2 & 2 & 2\end{array}$

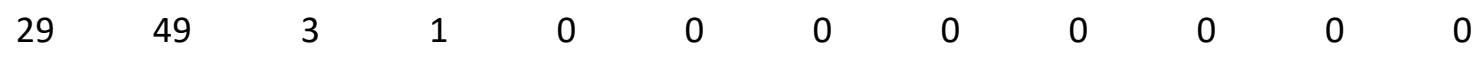

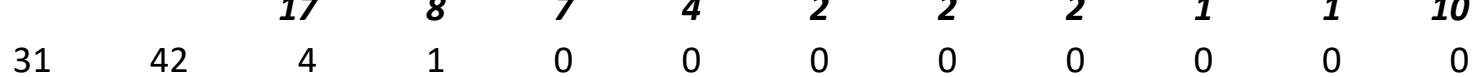
$\begin{array}{llllllllll}10 & 3 & 1 & 1 & 1 & 1 & 0 & 0 & 0 & 0\end{array}$ $\begin{array}{llllllllllll}32 & 62 & 5 & 1 & 0 & 0 & 0 & 0 & 0 & 0 & 0 & 0\end{array}$ $\begin{array}{llllllllll}25 & 12 & 7 & 6 & 5 & 2 & 0 & 0 & 0 & 0\end{array}$ $\begin{array}{llllllllllll}33 & 46 & 3 & 1 & 0 & 0 & 0 & 0 & 0 & 0 & 0 & 0\end{array}$ $\begin{array}{llllllllll}19 & 12 & 9 & 6 & 4 & 3 & 3 & 2 & 2 & 2\end{array}$ $\begin{array}{llllllllllll}34 & 10 & 1 & 0 & 0 & 0 & 0 & 0 & 0 & 0 & 0 & 0\end{array}$ $\begin{array}{lllllllllll}35 & 14 & 1 & 0 & 0 & 0 & 0 & 0 & 0 & 0 & 0\end{array}$ $\begin{array}{lllllllllll} & 2 & 0 & 0 & 0 & 0 & 0 & 0 & 0 & 0 & 0\end{array}$ $\begin{array}{lllllllllll}170 & 13 & 3 & 1 & 0 & 0 & 0 & 0 & 0 & 0 & 0\end{array}$

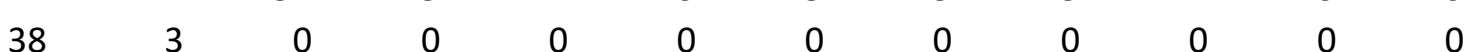
$\begin{array}{llllllllll}1 & 0 & 0 & 0 & 0 & 0 & 0 & 0 & 0 & 0\end{array}$ $\begin{array}{llllllllllll}39 & 399 & 30 & 4 & 2 & 1 & 0 & 0 & 0 & 0 & 0 & 0\end{array}$ $\begin{array}{llllllllll}148 & 88 & 54 & 35 & 27 & 21 & 17 & 15 & 13 & 9\end{array}$

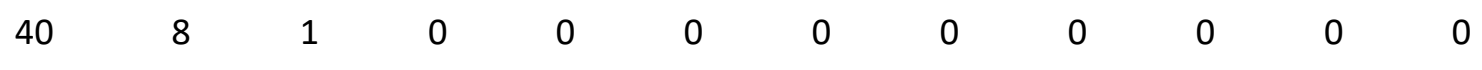

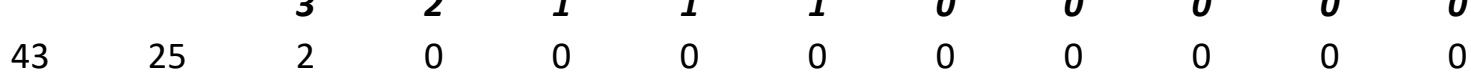
$\begin{array}{rlllllllll}8 & 3 & 1 & 0 & 0 & 0 & 0 & 0 & 0 & 0\end{array}$ $\begin{array}{llllllllllll}44 & 81 & 5 & 1 & 0 & 0 & 0 & 0 & 0 & 0 & 0 & 0\end{array}$

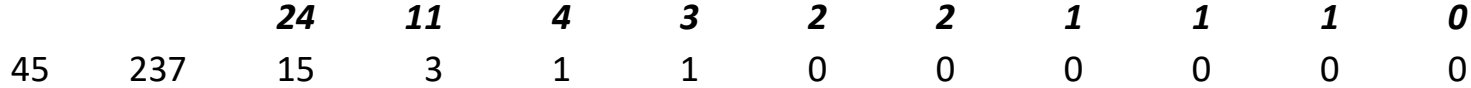
$\begin{array}{llllllllll}99 & 59 & 43 & 32 & 24 & 20 & 18 & 13 & 12 & 10\end{array}$ 
$\begin{array}{llllllllllll}46 & 257 & 18 & 3 & 1 & 0 & 0 & 0 & 0 & 0 & 0 & 0\end{array}$ $\begin{array}{llllllllll}103 & 58 & 41 & 26 & 21 & 18 & 14 & 10 & 9 & 9\end{array}$

$\begin{array}{llllllllllll}47 & 270 & 17 & 3 & 1 & 0 & 0 & 0 & 0 & 0 & 0 & 0\end{array}$ $\begin{array}{llllllllll}122 & 77 & 53 & 39 & 33 & 24 & 21 & 19 & 16 & 11\end{array}$ $\begin{array}{llllllllllll}48 & 231 & 20 & 5 & 1 & 1 & 0 & 0 & 0 & 0 & 0 & 0\end{array}$ $\begin{array}{llllllllll}87 & 47 & 30 & 23 & 18 & 12 & 7 & 5 & 5 & 4\end{array}$ $\begin{array}{llllllllllll}49 & 42 & 2 & 1 & 0 & 0 & 0 & 0 & 0 & 0 & 0 & 0\end{array}$ $\begin{array}{llllllllll}8 & 3 & 1 & 0 & 0 & 0 & 0 & 0 & 0 & 0\end{array}$

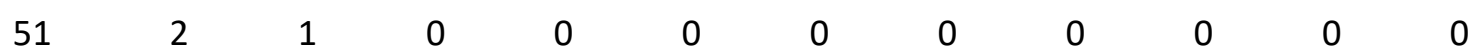

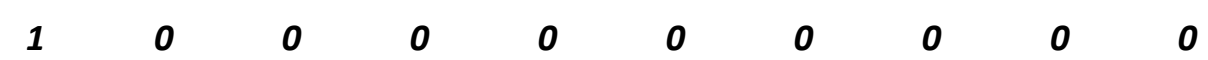
$\begin{array}{llllllllllll}54 & 175 & 14 & 3 & 1 & 0 & 0 & 0 & 0 & 0 & 0 & 0\end{array}$ $\begin{array}{llllllllll}70 & 45 & 28 & 21 & 16 & 14 & 12 & 11 & 8 & 7\end{array}$ $\begin{array}{rlllllllllll}55 & 1 & 0 & 0 & 0 & 0 & 0 & 0 & 0 & 0 & 0 & 0\end{array}$ $\begin{array}{llllllllll}56 & 18 & 2 & 1 & 0 & 0 & 0 & 0 & 0 & 0\end{array}$

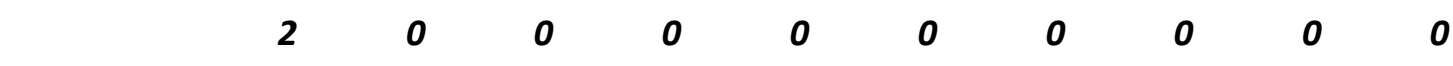
$\begin{array}{llllllllllll}58 & 107 & 9 & 2 & 1 & 0 & 0 & 0 & 0 & 0 & 0 & 0\end{array}$ $\begin{array}{llllllllll}47 & 30 & 21 & 16 & 13 & 10 & 9 & 6 & 6 & 6\end{array}$ $\begin{array}{llllllllllll}63 & 4 & 1 & 0 & 0 & 0 & 0 & 0 & 0 & 0 & 0 & 0\end{array}$ $\begin{array}{llllllllllll}65 & 235 & 31 & 7 & 3 & 1 & 1 & 0 & 0 & 0 & 0 & 0\end{array}$ $\begin{array}{llllllllll}65 & 24 & 15 & 10 & 4 & 3 & 3 & 1 & 1 & 1\end{array}$ $\begin{array}{rlllllllll}0 & 0 & 0 & 0 & 0 & 0 & 0 & 0 & 0 & 0 \\ 0 & 0 & 0 & 0 & 0 & 0 & 0 & 0 & 0 & 0\end{array}$ $\begin{array}{llllllllllll}67 & 77 & 10 & 2 & 1 & 0 & 0 & 0 & 0 & 0 & 0 & 0\end{array}$ $\begin{array}{llllllllllll}68 & 112 & 13 & 3 & 1 & 1 & 0 & 0 & 0 & 0 & 0 & 0\end{array}$ $\begin{array}{llllllllll}51 & 30 & 21 & 16 & 12 & 9 & 8 & 6 & 5 & 4\end{array}$ $\begin{array}{llllllllllll}71 & 2 & 0 & 0 & 0 & 0 & 0 & 0 & 0 & 0 & 0 & 0\end{array}$ $\begin{array}{llllllllllll}72 & 53 & 0 & 0 & 0 & 0 & 0 & 0 & 0 & 0 & 0 & 0 \\ & 6 & 1 & 1 & 0 & 0 & 0 & 0 & 0 & 0 & 0\end{array}$ $\begin{array}{llllllllll}15 & 6 & 4 & 2 & 2 & 0 & 0 & 0 & 0 & 0\end{array}$ $\begin{array}{llllllllllll}74 & 2 & 1 & 0 & 0 & 0 & 0 & 0 & 0 & 0 & 0 & 0\end{array}$ $\begin{array}{llllllllllll}76 & 29 & 4 & 1 & 1 & 0 & 0 & 0 & 0 & 0 & 0 & 0\end{array}$ $\begin{array}{rllllllllll}77 & 13 & 9 & 6 & 4 & 4 & 2 & 2 & 2 & 1 & 1\end{array}$ $\begin{array}{llllllllllll}77 & 2 & 1 & 0 & 0 & 0 & 0 & 0 & 0 & 0 & 0 & 0\end{array}$

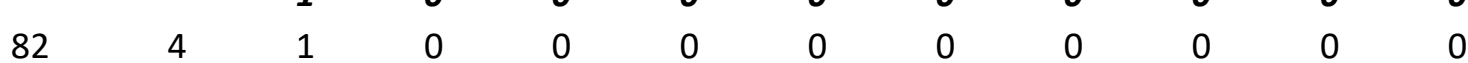

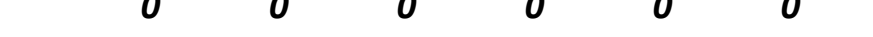
$\begin{array}{llllllllllll}83 & 21 & 3 & 1 & 0 & 0 & 0 & 0 & 0 & 0 & 0 & 0\end{array}$

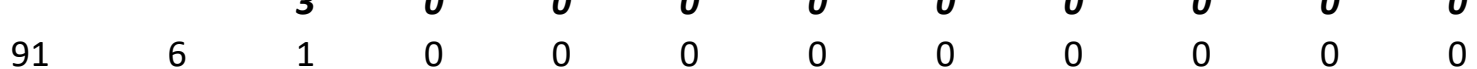
$\begin{array}{llllllllll}2 & 1 & 1 & 1 & 0 & 0 & 0 & 0 & 0 & 0\end{array}$ $\begin{array}{llllllllllll}92 & 69 & 9 & 2 & 1 & 0 & 0 & 0 & 0 & 0 & 0 & 0\end{array}$ $\begin{array}{llllllllll}24 & 13 & 7 & 4 & 4 & 3 & 3 & 3 & 1 & 1\end{array}$ 


$\begin{array}{llllllllllll}120 & 16 & 3 & 1 & 0 & 0 & 0 & 0 & 0 & 0 & 0 & 0 \\ & & 4 & 2 & 1 & 1 & 0 & 0 & 0 & 0 & 0 & 0\end{array}$

466

467

468 Supplementary information D. An example input data of genotype specific allele (GSA) (1)

469 and non-GSA SNPs (0) of contig 47 for GSA redistribution analysis of GSAs within a contig.

470 Each number represent a SNP within the 14 isolates (6 from Bramley, 8 from Worcester)

471

472

473

474

475

476

477

478

479

480

481

482

483

484

485

486

487

488

489

490

491

492

493

494

495

496

497

498

499

500

501

502

503

504

505

506

507

508

509

510

511

512

513

514

515

516

0000000000000000000000000000000000000000000000000000000000000000000000000000000000000000000 000000000000000000111111111100000111111000000000000000000000000000000000000000000000000000 000000000000000000000000001010011000000000000000000000000000000000000000000000000000000000 0000000000000000000000000000000000000000000000000000000000000000000000000000000000000000000 00000000000000000000000000000000000000000000000000000000000000000000000000000000000000000 00000000000000000000000000000000000000000000000000000000000000000000000000000000000000000 00000000000000000000000000000000000000000000000000000000000000000000000000000000000000000000 00000000000000000000000000000000000000000000000000000000000000000000000000000000000000000000 00000000000000000000000000000000000000000000000000000000000000000000000000000000000000000000 00000000000000000000000000000000000000000000000000000000000000000000000000000000000000000000 00000000000000000000000000000000000000000000000000000000000000000000000000000000000000000 00000000000000000000000000000000000000000000000000000000000000000000000000000000000000000 00000000000000000000000000000000000000000000000000000000000000000000000000000000000000000 00000000000000000000000000000000000000000000000000000000000000000000000000000000000000000 00000000000000000000000000000000000000000000000000000000000000000000000000000000000000000000 00000000000000000000000000000000000000000000000000000000000000000000000000000000000000000000 00000000000000000000000000000000000000000000000000000000000000000000000000000000000000000000 00000001100101111000000000000000000000000000000000000000000000000000000000000000000000000 000000000000000000000000000000000000000000000000000000000000000000000000000000000000000000 00000000000000000000000000000000000000000000000000000000000000000000000000000000000000000 00000000000000000000000000000000000000000000000000000000000000000000000000000000000000000 0000000000000000000000000000000000000000000000000000000000000000000000000000000000000000000 00000000000000000000000000000000000000000000000000000000000000000000000000000000000000000000 00000000000000000000000000000000000000000000000000000000000000000000000000000000000000000000 00000000000000000000000000000000000000000000000000000000000000000000000000000000000000000 000000000000000000000000000000000000000000000000000000000000000000000000000000000000000000 00000000000000000000000000000000000000000000000000000000000000000000000000000000000000000 00000000000000000000000000000000000000000000000000000000000000000000000000000000000000000000 00000000000000000000000000000000000000000000000000000000000000000000000000000000000000000000 00000000000000000000000000000000000000000000000000000000000000000000000000000000000000000000 00000000000000000000000000000000000000000000000000000000000000000000000000000000000000000000 00000000000000000000000000000000000000000000000000000000000000000000000000000000000000000 00000000000000000000000000000000000000000000000000000000000000000000000000000000000000000 00000000000000000000000000000000000000000000000000000000000000000000000000000000000000000 0000000000000000000000000000000000000000000000000011100000000000000000000000000000000000000 0000000000000000000000000000000000000000000000000000000000000000000000000000000000000000000 00000000000000000000000000000000000000000000000000000000000000000000000000000000000000000000 00000000000000000000000000000000000000000000000000000000000000000000000000000000000000000 00000000000000000000000000000000000000000000000000000000000000000000000000000000000000000 00000000000000000000000000000000000000000000000000000000000000000000000000000000000000000 00000000000000000000000000000000000000000000000000000000000000000000000000000000000000000 000000000000000000000000000000000000000000000000000000000000000000000000000000000000000000 000000000000000000000000000000000000000000000000000000000000000111010111111111111111111111 00111011111111111111111111011111111111110111111011111111111111111110001111111111111111111 
0111111111111111111100000000000000000000000000000000000000000000000000000000000000000000000 00000000000000001100000000000000000000000000000000000000000000000000000000000000000000000000 00000001001000000000000000000000000000000000000000000000000000000000000000000000000000000100 00000000000000000000000000000000000000000000000000000000000000000000000000000000000000011 11001001000100011100000001000000000000000000000000000000000000000000000000000000000000000 0000000000000000000000000000000000000000000000000000000000000000000000000000000000000000000 000000000000000000000000000000000000000000000000000000000000000000000000000000000000000000 00000000000000000000000000000000000000000000000000000000000000000000000000000000000000000000 000000000000000000000000000000000000000000000000000000000000000000000000000000000000000000 00000000000000000000000000000000000000000000000000000000000000000000000000000000000000000000 0000000000000000000000000000000000000000000000000000000000000000000000000000000000000000000 00000000000000000000000000000000000000000000000000000000000000000000000000000000000000000000 00000000000000000000000000000000000000000000000000000000000000000000000000000000000000000000 00000000000000000000000000000000000000000000000000000000000000000000000000000000000000000 00000000000000000000000000000000000000000000000000000000000000000000000000000000000000000000 00000000000000000000000000000000011111110000000000000111111110000000000000111111111111111 111111111111111111111111111111111111101110110111111111111111111111000000000000000000000000 000000000000000000000000000000000000000000000000000000000000000000000000000000000000000000 00000000000000000000000000000000000000000000000000000000000000000000000000000000000000000 00000000000000000000000000000000000000000000000000000000000000000000000000000000000000000000 00000000000000000000000000000000000000000000000000000000000000000000000000000000000000000 00000000000000000000000000000000000000000000000000000000000000000000000000000000000000000000 00000000000000000000000000000000000000000000000000000000000000000000000000000000000000000000 00000000000000000000000000000000000000000000000000000000000000000000000000000000000000000000 00000000000000000000000000000000000000000000000000000000000000000000000000000000000000000 00000000000000000000000000000000000000000000000000000000000000000000000000000000000000000 00000000000000000000000000000000000000000000000000000000000000000000000000000000000000000 00000000000000000000000000000000000000000000000000000000000000000000000000000000000000000000 00000000000000000000000000000000000000000000000000000000000000000000000000000001000000000000 00000000000000000000000000000000000000000000000000000000000000000000000000000000000000000000 00000000000000000000000000000000000000001000000011110010000000000000000000000000010000000 00000000000000000000000000000000000000000000000000000000000000000000000000000000000000000000 00000000000000000000000000000000000000000000000000000000000000000000000000000000000000000 00000000000000000000000000000000000000000000000000000000000000000000000000000000000000000 00000000000000000000000000000000000000000000000000000000000000000000000000000000000000000000 00000000000000000000000000000000000000000000000000000000000000000000000000000000000000000000 00000000000000000000000000000000000000000000000000000000000000000000000000000000000000000000 0000000000000000000000000000000000000000000000000000000000000000000000000000000000000000000 00000000000000000000000000000000000000000000000000000000000000000000000000000000000000000000 00000000000000000000000000000000000000000000000000000000000000000000000000000000000000000 00000000000000000000000000000000000000000000000000000000000000000000000000000000000000000 00000000000000000000000000000000000000000000000000000000000000000000000000000000000000000000 00000000000000000000000000000000000000000000000000000000000000000000000000000000000000000000 00000000000000000000000000000000000000000000000000000000000000000000000000000000000000000000 00000000000000000000000000000000000000000000000000000000000000000000000000000000000000000 00000000000000000000000000000000000000000000000000000000000000000000000000000000000000000000 00000000000000000000000000000000000000000000000000000000000000000000000000000000000000000 00000000000000000000000000000000000000000000000000000000000000000000000000000000000000000 0000000000000000000000000000000000000000000000000000000000000000000000000000000000000000000 00000000000000000000000000000000000000000000000000000000000000000000000000000000000000000000 


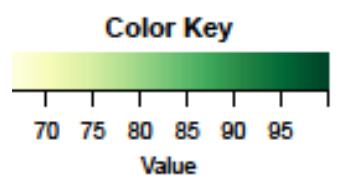

\begin{tabular}{|c|c|c|c|c|c|c|c|c|c|c|c|c|c|c|c|c|c|c|c|c|c|}
\hline 68.3 & 68.3 & 68.1 & 68.4 & 68.7 & 69.1 & 69.7 & 69.7 & 69.6 & 69.6 & 67.2 & 67.3 & 68.9 & 68.9 & 68.3 & 68.5 & 68.9 & 692 & 69.3 & 69.8 & 100 & B007 \\
\hline 67.1 & 66.8 & 67.6 & 67 & 67.5 & 68 & 68 & 68 & 68 & 68 & 67.4 & 67.5 & 68.6 & 68.6 & 68.6 & 68.5 & 68.2 & 692 & 69.3 & 100 & 69.8 & B025 \\
\hline 67.8 & 67.6 & 68.5 & 68.7 & 68.4 & 68.9 & 68.8 & 68.8 & 68.8 & 68.8 & 68.1 & 68.2 & 68.9 & 69 & 68.7 & 68.5 & 68.5 & 68.4 & 100 & 69.3 & 693 & BO44 \\
\hline 67.5 & 67.8 & 682 & 68.2 & 67.8 & 68.5 & 68.5 & 68.6 & 68.5 & 68.5 & 67.2 & 672 & 70.4 & 70.4 & 67 & 68.2 & 67.8 & 100 & 68.4 & 692 & 692 & C096 \\
\hline 67.2 & 66.7 & 67.4 & 66.9 & 67 & 678 & 67.8 & 67.8 & 6.8 & 67.8 & 67.2 & 67.3 & 68.1 & 68.1 & 68.4 & 67.1 & 100 & 67.8 & 68.5 & 682 & 689 & C119 \\
\hline 67 & 67.2 & 67.8 & 67.8 & 67.5 & 68.1 & 68 & 68 & 68 & 68 & 67.1 & 672 & 68.8 & 68.8 & 69.3 & 100 & 67.1 & 682 & 68.5 & 68.5 & 68.5 & C097 \\
\hline 67 & 66.1 & 67.3 & 66.9 & 67.3 & 67.6 & 67.9 & 67.9 & 5.9 & 67.9 & 67.3 & 67.4 & 68.5 & 68.5 & 100 & 69.3 & 68.4 & 67 & 68.7 & 68.5 & 68.3 & B199 \\
\hline 66.8 & 67 & 68.1 & 67.7 & 67.9 & 68.6 & 68.4 & 68.4 & 68.4 & 68.4 & 67.1 & 672 & 99.8 & 100 & 68.5 & 68.8 & 68.1 & 70.4 & 69 & 68.5 & 689 & B030 \\
\hline 66.7 & 67 & 68 & 67.7 & 67.8 & 68.5 & 68.4 & 68.4 & 68.4 & 68.4 & 67 & 67.1 & 100 & 99.8 & 68.5 & 68.8 & 68.1 & 70.4 & 68.9 & 68.5 & 689 & B024 \\
\hline 68.4 & 69.2 & 69.7 & 68.8 & 69.5 & 69.7 & 69.7 & 69.6 & 69.6 & 69.6 & 99.2 & 100 & 67.1 & 67.2 & 67.4 & 67.2 & 67.3 & 672 & 68.2 & 67.5 & 673 & $\mathrm{CO} 3$ \\
\hline 68.3 & 69.2 & 69.5 & 68.6 & 69.3 & 69.5 & 69.4 & 69.4 & 69.3 & 69.4 & 100 & 99.2 & 67 & 67.1 & 67.3 & 67.1 & 67.2 & 672 & 68.1 & 67.4 & 672 & C101 \\
\hline$\pi 7.3$ & 78.2 & 799 & 79 & 80.9 & 89.8 & 99.9 & 100 & 100 & 100 & 69.4 & 69.6 & 68.4 & 68.4 & 67.9 & 68 & 67.8 & 685 & 68.8 & 68 & 69.6 & W197 \\
\hline$\pi .3$ & 78.2 & 799 & 79 & 80.9 & 99.8 & 99.9 & 100 & 100 & 100 & 69.3 & 69.6 & 68.4 & 68.4 & 67.9 & 68 & 67.8 & 68.5 & 68.8 & 68 & 69.6 & W196 \\
\hline 77.3 & 78.2 & 799 & 79 & 80.9 & 899 & 99.9 & 100 & 100 & 100 & 69.4 & 69.5 & 68.4 & 68.4 & 67.9 & 68 & 67.8 & 68.6 & 68.8 & 68 & 69.7 & CO98 \\
\hline 77.3 & 78.2 & 799 & 79 & 80.9 & 89.8 & 100 & 99.9 & 99.9 & 99.9 & 69.4 & 69.7 & 68.4 & 68.4 & 67.9 & 68 & 67.8 & 68.5 & 68.8 & 68 & 69.7 & W172 \\
\hline 78.7 & 78.7 & 95.7 & 80.7 & 80.8 & 100 & 89.8 & 89.9 & 89.8 & 89.8 & 69.5 & 69.7 & 68.5 & 68.6 & 67.6 & 68.1 & 67.8 & 685 & 68.9 & 68 & 69.1 & W190 \\
\hline 77.6 & 7.7 & 789 & 83.8 & 100 & 80.8 & 80.9 & 80.9 & 809 & 80.9 & 69.3 & 69.5 & 67.8 & 67.9 & 67.3 & 67.5 & 67 & 67.8 & 68.4 & 67.5 & 68.7 & W049 \\
\hline 7.7 & 77.8 & 809 & 100 & 83.8 & 80.7 & 79 & 79 & 79 & 79 & 68.6 & 68.8 & 67.7 & 67.7 & 669 & 67.8 & 66.9 & 682 & 68.7 & 67 & 68.4 & W173 \\
\hline 79 & 78.1 & 100 & 80.9 & 78.9 & 85.7 & 79.9 & 79.9 & 799 & 79.9 & 69.5 & 69.7 & 68 & 68.1 & 67.3 & 67.8 & 67.4 & 682 & 68.5 & 67.5 & 68.1 & W182 \\
\hline 77.2 & 100 & 78.1 & 77.8 & 77.7 & 78.7 & 78.2 & 78.2 & 782 & 78.2 & 69.2 & 69.2 & 67 & 67 & 66.1 & 67.2 & 66.7 & 67.8 & 67.6 & 66.8 & 683 & C106 \\
\hline 100 & 77.2 & 79 & 77.7 & 77.6 & 78.7 & 77.3 & 77.3 & $\pi / 3$ & 77.3 & 68.3 & 68.4 & 66.7 & 66.8 & 67 & 67 & 67.2 & 67.5 & 67.8 & 67.1 & 683 & W202 \\
\hline స్ & $\frac{8}{0}$ & $\sum_{\text {\} }^{\infty}} &{\sum_{3}^{R}} &{\text { ईे }} &{\frac{\text { \%ి }}{3}} &{\sum_{j}^{N}} &{\text { : }} &{\sum_{3}^{\mathscr{\Phi}}} &{\frac{\hat{\sigma}}{3}} &{\text { 웅 }} &{\text { ర్లై }} &{\text { ఫ్థ }} &{\text { ర్ర్థి }} &{\frac{\%}{\infty}} &{\text { 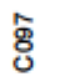 }} &{\frac{9}{\frac{\pi}{0}}} &{\text { : }} &{\text { d্ }} &{\text { జ్ర్థ }} &{\text { हे }} &{ } \\
$\hline
\end{tabular}

Figure 1. Heatmap to represent clustering of $21 \mathrm{~V}$. inaequalis isolates from three different apple cultivars, Bramley (B), Cox (C) and Worcester

(W), present in the same orchard. Data from identity-by-state (IBS) calculated on the percentage similarity of shared alleles between samples to produce a SNP matrix (the darker the shading the more alike the isolates). Due to rounding percentage values, several isolates showed "100\%" IBS; examining unfiltered SNPs showed that there are no isolates that have an identical set of SNPs. 


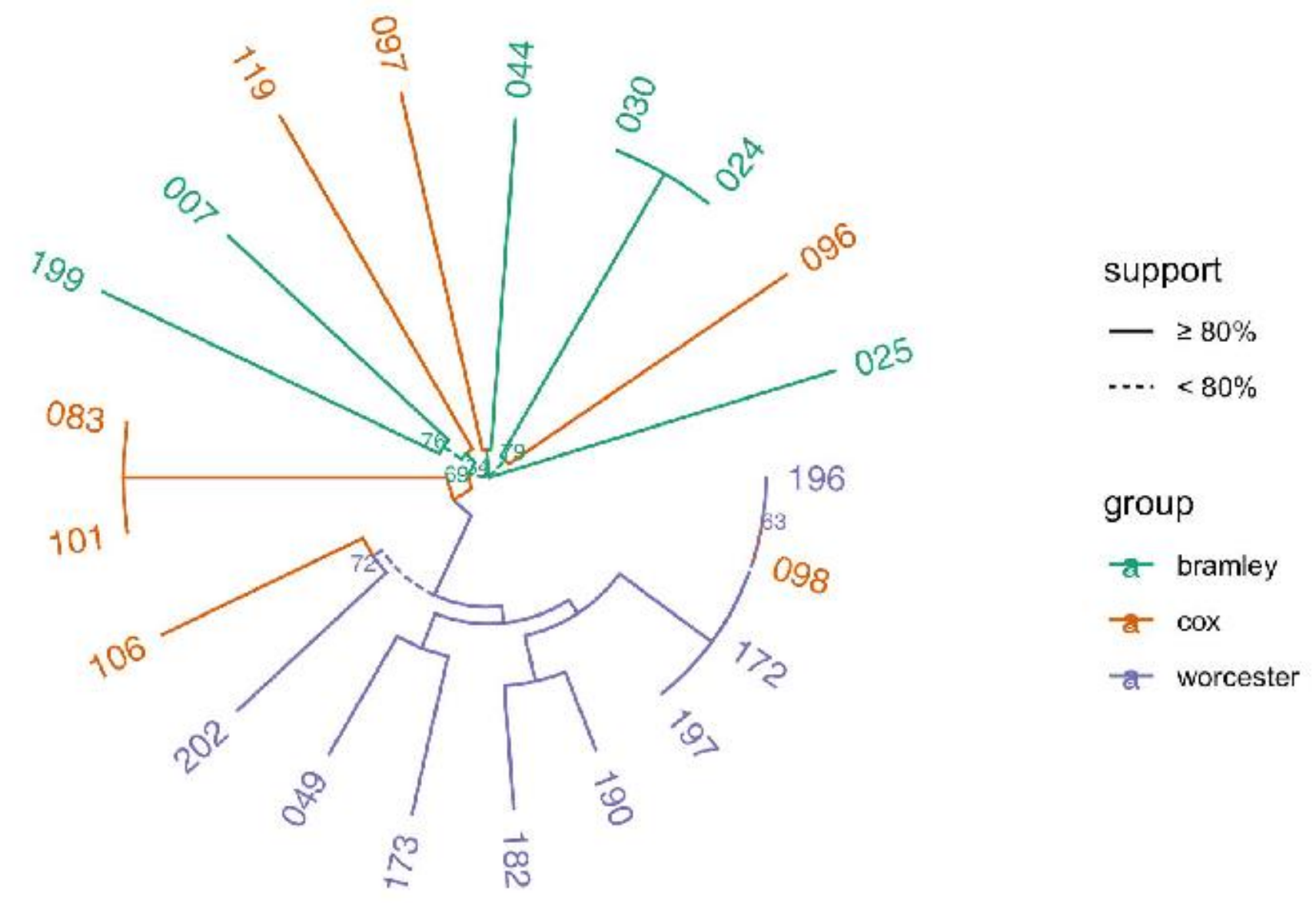

Figure 2. A Neighbour joining (NJ) tree, in polar format, showing clustering of Venturia inaequalis isolates from three different apple cultivars,

580 Bramley, Cox and Worcester, present in the same orchard. 

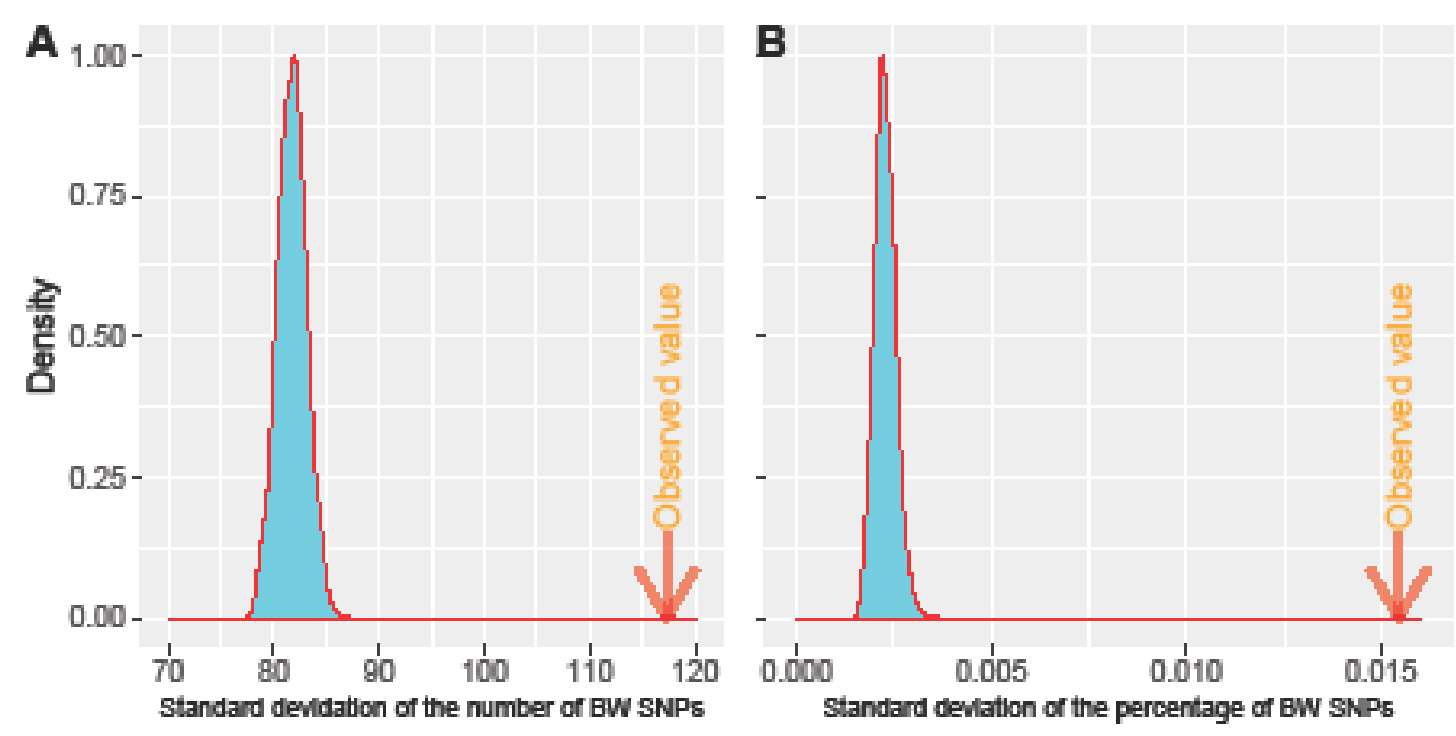

Figure 3. Plots of standard deviation of (A) the number of Bramley-Worcester genotype specific allele (GSA) loci and (B) the number of

Bramley-Worcester GSA as the percentage of total number of Cox-Bramley-Worcester GSA on each contig under the assumption of random 